\title{
The Relationship between Hypoalbuminemia and Intradialytic Hypotension in Haemodialysis Patients
}

Kora $\mathbf{M}^{1}$, Tawfeek $\mathbf{A}^{1}$, El-Zorkany $\mathrm{K}^{1}$ and AbdEI-Mohsen $\mathrm{AH}^{\mathbf{2}^{*}}$

${ }^{1}$ Department of Internal Medicine, Faculty of Medicine, Menoufia University, Menoufia, Egypt

${ }^{2}$ Department of Internal Medicine, Ashmoun General Hospital, Ashmoun, Menoufia, Egypt

"Corresponding author: Asmaa Hosny AbdEl-Mohsen, Department of Internal Medicine, Ashmoun General Hospital, Ashmoun, Menoufia, Egypt, Tel: +201009009659; E-mail: reyad.rabea@vet.usc.edu.eg

Received Date: Mar 06, 2018; Accepted Date: Mar 16, 2018; Published Date: Mar 24, 2018

Copyright: (c) 2018 Kora M, et al. This is an open-access article distributed under the terms of the Creative Commons Attribution License, which permits unrestricted use, distribution, and reproduction in any medium, provided the original author and source are credited.

\begin{abstract}
Objective: To evaluate the relationship between Serum albumin and Intradialytic Hypotension (IDH).

Background: Hypoalbuminemia and Intradialytic Hypotension (IDH) is a common complication during HD session. Hypotension is a risk factor for mortality and morbidity in HD patients.

Patients and methods: We conducted a cross-sectional study on 50 patients with ESRD who received regular hemodialysis session 3 times weekly for more than 3 months (from April to July 2017) at Ashmoun General Hospital. They have been divided into two groups; Group 1: Patients of this group developed recurrent attacks of IDH and Group 2: Patients of this group did not develop IDH. Data collected from each patient included: (I) Demographic features, clinical features (blood pressure changes during session, ultrafiltration rate, intradialytic weight gain (IDWG), duration of dialysis, cause of ESRD, surface area of dialyzer and blood flow of the machine), (II) Blood chemistry (creatinine, urea, hemoglobin, hematocrit value, albumin, triglycerides, cholesterol, AST, ALT, $\mathrm{Na}^{*}, \mathrm{~K}^{*}$ and KT/V), (III) Echocardiographic assessment of left ventricular geometry and (IV) IVC guided ultrasonography.
\end{abstract}

Result: Serum albumin level among group I ranged between 2.4-4.7 mg/dl with mean \pm SD $3.1 \pm 0.53 \mathrm{mg} / \mathrm{dl}$, while in group II serum albumin level ranged between $2.6-4.6 \mathrm{mg} / \mathrm{dl}$ with mean $\pm \mathrm{SD} 3.6 \pm 0.48 \mathrm{mg} / \mathrm{dl}$ with $\mathrm{p}$-value 0.002 and there were a high significant difference between both groups.

Conclusion: We concluded that serum albumin is a parameter which is associated with intradialytic hypotension and found that beside measurement of IVCC and IVCD are easy and good markers for prediction of intradialytic hypotension.

Keywords: Haemodialysis; Hypoalbuminemia; Intradialytic hypotension; IVC diameter; Collapsibility index

\section{Introduction}

Acute complications commonly occur during routine hemodialysis treatments. They include the following: Hypotension, hypertension, cramps, nausea and vomiting, arrhythmia, chest pain, sudden death, headache, seizure and bleeding diathesis [1]. IDH is due to impaired plasma volume refilling (too high ultrafiltration, autonomic dysfunction), decreased cardiac reserve (diastolic or systolic dysfunction), impaired venous compliance, autonomic dysfunction (diabetes, uremia), arrhythmias, anemia, drug therapy (vasodilators, $B$ blockers, calcium channel blockers), alteration of vasoactive substances in blood (low NO, high endothelin-1 and angiotensin-2), eating during treatment (increased splanchnic blood flow), too low target weight estimation [2].

IDH continues to be a leading problem, especially in elderly and cardiovascular compromised patients [3]. The association between blood pressure changes and death rate is higher in hemodialysis patients to be an independent and negative predictor of long-term fistula outcome [4].
The sensitivity of patients for IDH may not be a stable condition. Many patients were found to have large differences in the incidence of IDH over a 24 month period [5]. Hypoalbuminemia is an important risk factor of hypotension during hemodialysis [6]. Also, hypoalbuminemia was an important risk factor for progressive left ventricular hypertrophy in patients with End Stage Renal Disease (ESRD) [7]. Hypoalbuminemia and dialysis efficacy have been shown repeatedly to be perhaps the most critical predictors of outcomes in patients with ESRD. The relationship between hypoalbuminemia and mortality was especially present; each $1 \mathrm{gm} / \mathrm{dl}$ decrease in mean serum albumin is associated with the development of de novo and recurrent cardiac failure, de novo and recurrent ischemic heart disease, cardiac mortality and overall mortality [8].

The aim of this study was the relationship between hypoalbuminemia and IDH in HD patients.

\section{Patients and Methods}

\section{Study population}

This study was done in the dialysis unit at Ashmoun General Hospital on patients with ESRD on regular hemodialysis (HD) for 
Citation: Kora M, Tawfeek A, El-Zorkany K, AbdEI-Mohsen AH (2018) The Relationship between Hypoalbuminemia and Intradialytic Hypotension in Haemodialysis Patients. J Kidney 4: 165. doi:10.4172/2472-1220.1000165

Page 2 of 5

more than 3 months. All was given informed consent and the study approved by ethics committee of Menoufia University.

\section{Study groups}

This study was conducted on 50 patients with ESRD who received regular hemodialysis session 3 times weekly for more than 3 months at Ashmoun General Hospital. The selected 50 patients were classified into 2 groups according to presence of IDH; Group (I) included 24 patients who had IDH and group. Group (II) included 26 patients who does not have IDH.

\section{Study design}

All patients were examined for: History, clinical examination, dialysis data, laboratory investigation, echocardiography and ultrasound on the IVC.

\section{Inclusion criteria}

ESRD patients maintained on haemodialysis more than 3 months, 3 times weekly, each session was of $4 \mathrm{hrs}$.

\section{Exclusion criteria}

Decompensated chronic liver disease, severe inflammation and/or active infection.

\section{Statistical analysis}

Data were analyzed using the statistical program for the social sciences (SPSS, version 20.0; IBM, Armonk, New York, USA). Quantitative data were expressed as mean \pm SD and qualitative data were expressed as frequency and percentage.

The following tests were conducted: Independent sample t-test of significance was used when comparing between two means; the c2-test of significance was used to compare proportions between two qualitative parameters and Pearson's correlation coefficient (r) test was used for correlating data.

$\mathrm{P}$ values were interpreted as follows: $\mathrm{P}$ value less than or equal to 0.05 was considered significant.

\section{Result}

Patients who had IDH, among 50 patients there were 13(26\%) females and $37(74 \%)$ male patients.

Group I were 9(18\%) females and $15(30 \%)$ male patients and group II were $4(8 \%)$ females and $22(44 \%)$ males patients with p-value 0.07 and there were no significant difference between both groups.

Patients who had IDH (group I), among 50 patients there were $7(14 \%)$ diabetic, $14(28 \%)$ hypertensive, $8(16 \%)$ hepatitis $\mathrm{C}$ virus and $3(6 \%)$ congestive heart failure patients and group II who had no IDH (group II), among 50 patients there were 5(10\%) diabetic, 13(26\%) hypertensive, $4(8 \%)$ hepatitis $\mathrm{C}$ virus and $1(2 \%)$ congestive heart failure patients with P-value $(0.31,0.38,0.12$ and 0.28 respectively) and there were no significant difference between both groups as regard presence of associated comorbidities (DM, HTN, HCV and CHF).

Regarding these studies there were no significant difference between both groups on the basis of the age ( $\mathrm{p}$-value $=0.06$ ), duration of dialysis $(\mathrm{p}$-value $=0.76)$ and BMI $(\mathrm{p}$-value $=0.683)($ Table 1$)$

\begin{tabular}{|c|c|c|c|c|}
\hline & $\begin{array}{l}\text { Group I } \\
(\mathrm{no}=24)\end{array}$ & $\begin{array}{l}\text { Group II } \\
\text { (no=26) }\end{array}$ & Utest & p-value \\
\hline $\begin{array}{l}\text { Age } \\
\text { Mean } \pm \text { S.D }\end{array}$ & $57.3 \pm 12.90$ & $50.0 \pm 16.17$ & 1.86 & 0.06 \\
\hline $\begin{array}{l}\text { Duration of } \\
\text { dialysis } \\
\text { Mean } \pm \text { S.D }\end{array}$ & $26.2 \pm 22.47$ & $33.4 \pm 34.79$ & 0.3 & 0.76 \\
\hline $\begin{array}{l}\text { BMI: (Body } \\
\text { Mass Index) } \\
\text { Mean } \pm \text { S.D }\end{array}$ & $28.8 \pm 8.95$ & $27.6 \pm 6.50$ & 0.408 & 0.683 \\
\hline
\end{tabular}

Table 1: Comparison between both groups as regard to age, BMI and duration of dialysis.

Regarding these studies there were a high significant difference between both groups on the basis of serum albumin level ( $\mathrm{p}$ value $=0.002)$, IVCD and IVCC (p-value $=<0.01)$ (Table 2$)$.

\begin{tabular}{|c|c|c|c|c|}
\hline & $\begin{array}{l}\text { Group I } \\
\text { (no=24) }\end{array}$ & $\begin{array}{l}\text { Group II } \\
\text { (no=26) }\end{array}$ & Utest & p-value \\
\hline $\begin{array}{l}\text { ALBUMIN } \\
\text { Mean } \pm \text { S.D }\end{array}$ & $3.1 \pm 0.53$ & $3.6 \pm 0.48$ & $3.231^{*}$ & $0.002^{* *}$ \\
\hline $\begin{array}{l}\text { SA } \\
\text { Mean } \pm \text { S.D }\end{array}$ & $1.59 \pm 0.21$ & $1.65 \pm 0.19$ & 0.982 & 0.326 \\
\hline $\begin{array}{l}\text { QB } \\
\text { Mean } \pm \text { S.D }\end{array}$ & $271.6 \pm 34.59$ & $263.4 \pm 35.77$ & 0.892 & 0.372 \\
\hline $\begin{array}{l}\text { UF } \\
\text { Mean } \pm \text { S.D }\end{array}$ & $2.5+0.98$ & $2.1 \pm 0.94$ & 1.3 & 0.187 \\
\hline $\begin{array}{l}\text { IDWG } \\
\text { Mean } \pm \text { S.D }\end{array}$ & $2.6+1.19$ & $2.2+0.98$ & 1.11 & 0.266 \\
\hline $\begin{array}{l}\text { KT/V } \\
\text { Mean } \pm \text { S.D }\end{array}$ & $1.2+0.35$ & $1.1+0.35$ & 1.16 & 0.244 \\
\hline $\begin{array}{l}\text { IVCD } \\
\text { Mean } \pm \text { S.D }\end{array}$ & $7.5 \pm 1.14$ & $8.5 \pm 0.73$ & 3.4 & $0.001^{* *}$ \\
\hline $\begin{array}{l}\text { IVCC } \\
\text { Mean } \pm \text { S.D }\end{array}$ & $57.8 \pm 7.18$ & $51.5 \pm 4.83$ & 3.1 & $0.002^{* *}$ \\
\hline
\end{tabular}

Utest: Mann-Whitney U test; *: t-Student Test; **: High Significant Test; SA: Surface Area of Dialyzer; QB: Blood Flow of the Machine; UF: Ultrafiltration; IDWG: Intradialytic Weight Gain; KT/V: Dialysis Adequacy; IVCD: Inferior Vena Cava Diameter; IVCC: Inferior Vena Cava Collapsibility Index

Table 2: Comparison between both groups as regard serum albumin, surface area of dialyzer, blood flow of machine, ultrafiltration during dialysis session, intradialytic weight gain, KT/V, IVCC and IVCD.

Regarding these studies there were no significant difference between both groups on the basis of SA ( $\mathrm{p}$-value $=0.326), \mathrm{QB}(\mathrm{p}$-value $=0.372)$, UF $\quad(\mathrm{p}$-value $=0.187), \quad$ IDWG $\quad(\mathrm{p}$-value $=0.266)$ and $\mathrm{KT} / \mathrm{V} \quad(\mathrm{p}-$ value $=0.244)($ Table 2$)$. 
There was a highly significant negative correlation between serum albumin and delta systolic blood pressure or IVC collapsibility index $(\mathrm{P}=<0.01)$ (Figures 1-3).

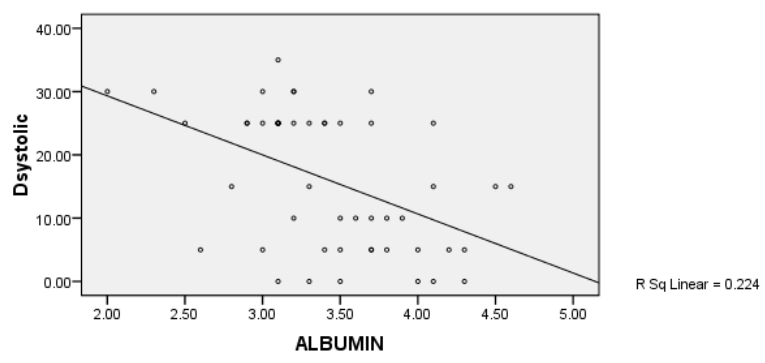

Figure 1: Shows the relationship between serum albumin and delta systolic blood pressure $(\mathrm{r}=-0.47$, $\mathrm{p}$-value $=<0.01)$.

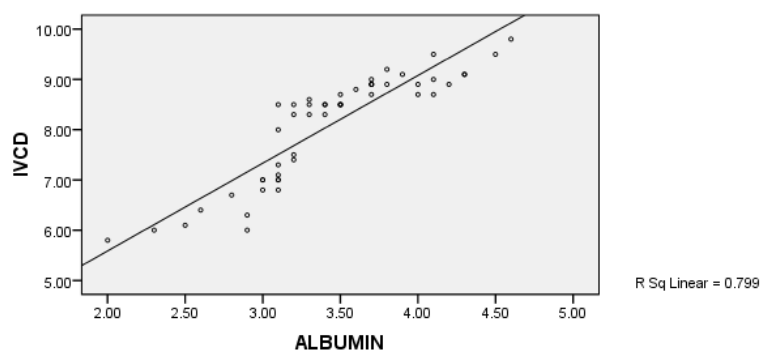

Figure 2: Shows the relationship between serum albumin and IVC diameter $(\mathrm{r}=0.894$, $\mathrm{p}$-value $\mathrm{P}=<0.01)$.

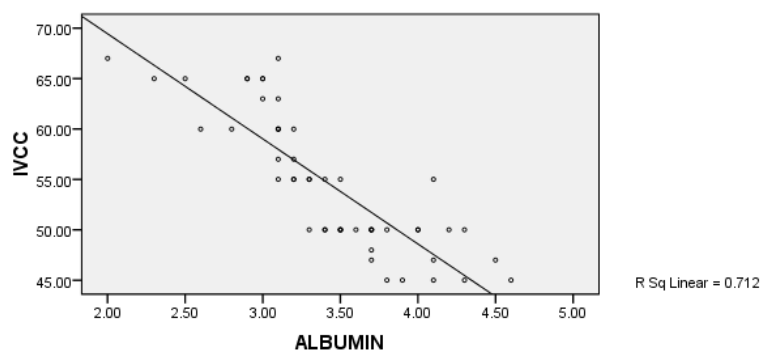

Figure 3: Shows the relationship between serum albumin and IVC collapsibility index $(\mathrm{r}=0.844$, $\mathrm{p}$-value $=<0.01)$.

There was a highly significant positive correlation between serum albumin and IVC diameter $(\mathrm{P}=<0.01)$ (Figure 2).

Receiver Operator Curve (ROC) for studying sensitivity and specificity of serum albumin, IVCD and IVCC as a predictor for IDH. The curve shows that IVCC is the only predictor for IDH which has a high sensitivity and specificity (Area under curve for IVCC $=79 \%$ ).

Cut off point $=52.5 \%$. At this cut off point, sensitivity of IVCC for detection of IDH=78\%, while specificity is $70 \%$ (Figure 4 ).

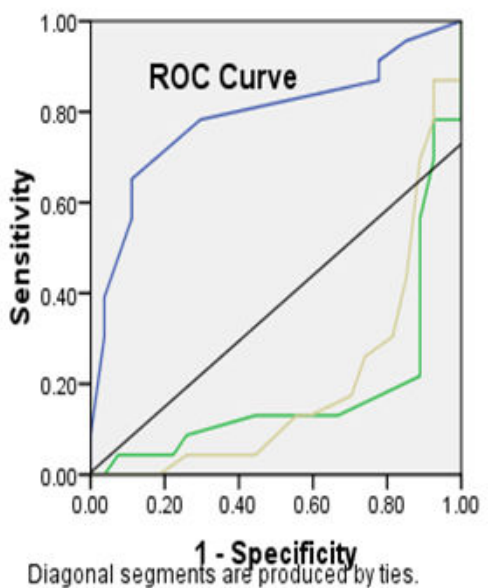

R Sq Linear $=0.558$

Figure 4: Shows receiver operator curve (ROC) for studying sensitivity and specificity of serum albumin, IVCD and IVCC as a predictor for IDH.

The curve shows that IVCC is the only predictor for IDH which has a high sensitivity and specificity (Area under curve for IVC=79\%). Cut off point $=52.5 \%$. At this cut off point, sensitivity of IVCC for detection of $\mathrm{IDH}=78 \%$, while specificity is $70 \%$.

\section{Discussion}

Intradialytic hypotension is a frequent complication of $\mathrm{HD}$ as a result of imbalance of intravascular volume removal and the inadequacy of hemodynamic compensatory mechanisms such as vascular shunting to the central circulation, increased vascular resistance in the splanchnic and cutaneous beds, increasing arterial tone and increasing cardiac output [9].

Hypoalbuminemia and dialysis intensity have been shown repeatedly to be perhaps the most critical predictors of outcomes in patients with end stage renal disease. The relationship between hypoalbuminemia and mortality was especially strong. In the Canadian study each $1 \mathrm{gm} / \mathrm{dl}$ decrease in mean serum albumin was independently associated with the development of de novo and recurrent cardiac failure, de novo and recurrent ischemic heart disease, cardiac mortality and overall mortality [8].

Hypoalbuminemia is a major risk factor of hypotension during HD in patients on $\mathrm{HD}$. One possibility of hypotension during $\mathrm{HD}$ is hypovolemia in blood vessels because of low osmolality [6].

Hypoalbuminemia leads to hypovolaemia due to decreased oncotic pressure. This lead to decreased plasma refill and causes premature drop in BP leading to IDH [6].

In the current study, there was no significant difference between the both groups regarding sex. This was in agreement with Locatelli et al. [10] who found that there was no significant difference between both groups as regards gender. On the other hand, there was disagreement with Tisler et al. [11] who found that IDH is more common in females, Stefánsson et al. [12] found that females are at a high risk for IDH. The incidence of IDH is higher in old age, hypotensive episodes occurred 
frequently in $44 \%$ of dialysis patients of $\geq 65$ years and in $32 \%$ of younger dialysis patients (age $<45$ years).

There was no significant difference between both groups as regards age of patients. This result is in agreement with Tayyebi et al. [13] who that found that there was no significant difference between age of patients and incidence of IDH. Long duration of hemodialysis might be associated with endothelial dysfunction. Also, vascular calcification, which increases with the duration of dialysis, might be responsible for the impairment of vasoconstriction and for arterial stiffness resulting in IDH [14]. Our study found that there was no significant difference between the two groups as regards duration of dialysis. This result is in an agreement with Tayyebi et al. [13] who found no significant effect between duration of dialysis and IDH. DM is a risk factor for IDH (especially if there is autonomic neuropathy) [2].

In our study, we found no significant correlation between blood flow and intradialytic hypotension. This result is in an agreement with Mc Causland et al. [15] who found no significant effect of increasing blood flow on blood pressure changes during hemodialysis session.

$\mathrm{KT} / \mathrm{V}$ is an important indicator of dialysis adequacy [16]. In our study we found no significant effect of IDH on KT/V. This finding was in agreement with Tayyebi et al. [13] who found no significant correlation between IDH and KT/V. In another study KT/V was taken as a target regardless time of hemodialysis session and patient who could get the optimal KT/V have been reported to have many times of hypotensive episodes during hemodialysis session [17].

In this study, we found a significant positive correlation between IDWG and delta systolic blood pressure. This result is in agreement with Rocha et al. [18] who found a significant correlation between IDWG and changes in blood pressure during session. Ultrafiltration is part of the hemodialysis procedure and can also be used exclusively to remove additional fluid in patients with fluid overload. Ultrafiltration that is too aggressive can result in hypotension, cramping, or other untoward effects [16].

Our study revealed that found a significant positive correlation between UF and delta systolic blood pressure. This result is in agreement with Koomans et al. [19] in which there was a significant correlation between UF and changes in blood pressure during session.

In our study, we found that there was no significant difference between both groups as regards hemoglobin and hematocrit value. This result is in agreement with Mc Causland et al. [15] who found that there is no effect of hemoglobin and hematocrit value on IDH. Also, Tisler et al. [11] found that there is no effect of anemia on IDH.

We found that there was no significant difference between both groups as regards cholesterol and triglyceride. This result was in agreement with Kraemer et al. [17] who found that no effect of dyslipidemia on IDH. Low serum potassium can have a direct vasoconstrictor effect [20]. In our study there is no significant association between potassium level and IDH.

In our study, we found that there was no significant difference between both groups regarding sodium level. This is in agreement with Kraemer et al. [17] who found that there was no effect of sodium level on IDH. On the other hand, the use of a higher dialysate sodium concentration $(>140 \mathrm{mEq} / \mathrm{L})$ is an effective means to ensure adequate vascular refilling and has proved to be among the most efficacious and best tolerated therapies for episodic hypotension [21].
In our study, we found that there was no significant difference between both groups regarding echocardiographic parameter. This finding was in disagreement with results obtained by Zhou et al. [21]. Ritz et al. [22] found that left ventricular hypertrophy predispose to IHD.

Delta blood pressure is a very important indicator of change of systolic blood pressure during dialysis session [6]. The increase of Delta SBP indicates more declines in blood pressure and consequently increase incidence of IHD. In the present work, we found a significant negative correlation between serum albumin and Delta BP.

Malnutrition, which is a common finding in ESRD patients, is a potential cause of reduced albumin synthesis, decreased albumin levels. Serum albumin is the strongest predictor of death in dialysis patients, and even in patients at baseline who are starting dialysis therapy.

Hypoalbuminemia is a major risk factor of hypotension during HD in patients on $\mathrm{HD}$. One possibility of hypotension during $\mathrm{HD}$ is hypovolemia in blood vessels because of low osmolality [6].

Hypoalbuminemia is a nontraditional risk factor for cardiovascular diseases (CVD) in HD patients [23]. So, hypoalbuminemia could be a factor, which accelerates IHD in those patients. In our study we found that there is a high significant negative correlation between albumin and IDH. This result is in agreement with Chou et al. [24], who found a high significant negative correlation between hypoabuminemia and changes in blood pressure during session. Also, Al-Etreby et al. [25] found that there was association between hypoalbuminemia and IDH.

IVCD and IVCC were found to be correlated significantly with hypervolemia in hemodialysis patient [26]. As serum albumin is a strong predictor of intra-vascular volume status, we tried to study the correlation between serum albumin and both of IVCC and IVCD. In our study we found a highly significant positive correlation between serum albumin and IVCD, however there was a highly significant negative correlation between serum albumin and IVCC.

The incidence of hypoalbuminemia is increased with aging. As the number of aging people has increased among hemodialysis patients the incidence of IDH [27].

\section{Conclusion}

We concluded that serum albumin is a parameter which is associated with intradialytic hypotension. Also, we found that IDWG is a risk for IDH. Also we found that bed side measurement of IVCC and IVCD are easy and good markers for prediction of intradialytic hypotension. Also, we predict that cut off point for IVCC $=52.5 \%$.

\section{References}

1. Magee CC, Tucker JK, Singh AK (2016) Core concepts in dialysis and continuous therapies. Springer 23: 39-51.

2. Straver B, De Vries PMJM, Donker AJM, Ter Wee PM (2002) The effect of profiled hemodialysis on intradialytic hemodynamics when a proper sodium balance is applied. Blood Purification 20: 364-369.

3. Foley RN, Parfrey PS (1997) Cardiac disease in chronic uremia: Clinical outcome and risk factors. Adv Chronic Kid Dis 4: 234-248.

4. Puskar D, Pasini J, Savic I, Bedalov G (2002) Survival of primary arteriovenous fistula in patient sonchronic hemodialysis. Croat Med J 43: 306-311. 
Citation: Kora M, Tawfeek A, El-Zorkany K, AbdEI-Mohsen AH (2018) The Relationship between Hypoalbuminemia and Intradialytic Hypotension in Haemodialysis Patients. J Kidney 4: 165. doi:10.4172/2472-1220.1000165

Page 5 of 5

5. Maggiore Q, Pizzarelli F, Dattolo P, Maggiore U, Cerrai T (2000) Cardiovascular stability during haemodialysis, haemofiltration and haemodiafiltration. Nephrol Dial Transplant 15: 68-73.

6. Nakamoto H, Honda N, Mimura T, Suzuki H (2006) Hypoalbuminemia is an important risk factor of hypotension during hemodialysis. Hemodialysis Int 10: 10-15.

7. Moon KH, Song IS, Yang WS, Shin YT, Kim SB, et al. (2000) Hypoalbuminemia as a risk factor for progressive left-ventricular hypertrophy in hemodialysis patients. Am J Nephrol 20: 396-401.

8. Foley RN, Parfrey PS, Harnett JD, Kent GM, Murray DC, et al. (1996) Impact of hypertension on cardiomyopathy, morbidity and mortality in end-stage renal disease. Kidney Int 49: 1379-1385.

9. Reilly RF (2014) Attending rounds: A patient with intradialytic hypotension. Clin J Am Soc Nephrol 9: 798-803.

10. Locatelli F, Altieri P, Andrulli S, Bolasco P, Sau G, et al. (2010) Hemofiltration and hemodiafiltration reduce intradialytic hypotension in ESRD. J Am Soc Nephrol 21: 1798-1807.

11. Tisler A, Akocsi K, Harshegyi I, Varga G, Ferenczi S, et al. (2002) Comparison of dialysis and clinical characteristics of patients with frequent and occasional hemodialysis-associated hypotension. Kidney Blood Press Res 25: 97-102.

12. Stefansson BV, Brunelli SM, Cabrera C, Rosenbaum D, Anum E, et al (2014) Intradialytic hypotension and risk of cardiovascular disease. Clin J Am Soc Nephrol 9: 2124-2132.

13. Tayyebi A, Shasti S, Tadrisi D, Eynollahi B, Sadeghi SM (2012) The relationship between blood pressure and dialysis adequacy in dialysis patients. Iranian J Crit Care Nursing 5: 49-52.

14. Floege J, Raggi P, Block GA, Torres PU, Csiky B, et al. (2010) Study design and subject baseline characteristics in the ADVANCE Study: Effects of cinacalcet on vascular calcification in haemodialysis patients. Nephrol Dial Transplant 25: 1916-1923.

15. Mc Causland FR, Brunelli SM, Waikar SS (2013) Dialysis dose and intradialytic hypotension: Results from the HEMO study. Am J Nephrol 38: 388-396.

16. Rezaiee O, Shahgholian N, Shahidi S (2016) Assessment of hemodialysis adequacy and its relationship with individual and personal factors. Iranian J Nursing Midwifery Res 21: 577-582.
17. Kraemer M, Rode C, Wizemann V (2006) Detection limit of methods to assess fluid status changes in dialysis patients. Kidney Int 69: 1609-1620.

18. Rocha A, Sousa C, Teles P, Coelho A, Xavier E (2016) Effect of dialysis day on intradialytic hypotension risk. Kidney Blood Press Res 41: 168-174.

19. Koomans HA, Geers AB, Mees EJD (1984) Plasma volume recovery after ultrafiltration in patients with chronic renal failure. Kidney Int 26: 848-854.

20. Chou KJ, Lee PT, Chen CL, Chiou CW, Hsu CY, et al. (2006) Physiological changes during hemodialysis in patients with intradialysis hypertension. Kidney Int 69: 1833-1838.

21. Zhou YL, Liu HL, Duan XF, Yao Y, Sun Y, et al. (2006) Impact of sodium and ultrafiltration profiling on haemodialysis-related hypotension. Nephrol Dial Transplant 21: 3231-3237.

22. Ritz E, Rambausek M, Mall G, Ruffmann K, Mandelbaum A (1990) Cardiac changes in uraemia and their possible relationship to cardiovascular instability on dialysis. Nephrol Dial Transplant 5: 93-97.

23. Choi MJ, Seo JW, Yoon JW, Lee SK, Kim SJ, et al. (2012) The malnutrition-inflammation-depression-arteriosclerosis complex is associated with an increased risk of cardiovascular disease and all cause death in chronic hemodialysis patients. Nephron Clinical Prac 122: 44-52.

24. Chou JA, Kalantar-Zadeh K, Mathew AT (2017) A brief review of intradialytic hypotension with a focus on survival. Seminars Dial 30: 473-480.

25. Al-Etreby EA, El-Aziz AA, El-Waseef O, El-Moselhy EA (2016) The association between hypoalbuminemia and intradialytic hypotension in haemodialysis patients. Egyptian J Hospital Med 63: 185-194.

26. Agarwal R, Kelley K, Light RP (2008) Diagnostic utility of blood volume monitoring in hemodialysis patients. Am J Kid Dis 5: 242-254.

27. Gomi I, Fukushima H, Shiraki M, Miwa Y, Ando T, et al. (2007) Relationship between serum albumin level and aging in communitydwelling self-supported elderly population. J Nutr Sci Vitaminol 53: $37-42$. 